\title{
A POESIA GOESA DE LÍNGUA PORTUGUESA NO CONTEXTO DAS LITERATURAS EM PORTUGUÊS
}

\author{
GOAN POETRY IN THE PORTUGUESE \\ LANGUAGE IN THE CONTEXT OF \\ LITERATURES IN PORTUGUESE
}

Hélder Garmes ${ }^{1}$

\section{RESUMO}

A poesia de língua portuguesa produzida em Goa, ex-colônia de Portugal na Índia, guarda vínculos estreitos com a poesia de língua portuguesa produzida em várias partes do mundo. Nosso intuito é explorar algumas conexões dessa poesia com a poesia brasileira e a moçambicana e apontar para a importância de se incluir essa literatura no âmbito dos estudos comparados de literaturas de língua portuguesa.

PALAVRAS-CHAVE: literatura goesa de língua portuguesa; literatura indo-portuguesa; literatura comparada.

\section{ABSTRACT}

Portuguese language poetry written in Goa, former Portuguese colony in India, is closely related to the Portuguese language poetry produced in different parts of the world. In this paper, our objective is to explore some of the connections of Goan poetry in Portuguese with Brazilian and Mozambican poetry in order to show the importance of including this little known literature within the scope of the comparative studies of Portuguese language literature.

KEYWORDS: Goan literature in Portuguese; Indo-Portuguese literature; comparative literature. 
Diferentemente do Brasil e de outras ex-colônias portuguesas, Goa, na Índia, teve imprensa já no século XVI, ali instalada pelos jesuítas no Colégio de São Paulo. Desde então, muitos portugueses escreveram sobre Goa, bastando lembrar, no âmbito da poesia, autores do peso de Luís Vaz de Camões e de Manuel Maria Barbosa du Bocage. Vale destacar, no início do século XVII, a publicação da Lusitânia transformada (1607), de Fernão Álvares do Oriente, uma novela pastoril que aborda a crise do império português. Trata-se de um longo texto de caráter moralista em prosa e verso, formado por três livros. No que se refere aos versos, contém 86 poemas em diversos estilos (elegias, sextinas, sonetos, éclogas etc.). Provavelmente foi todo escrito na Ásia, onde Fernão Álvares permaneceu por muitos anos. O protagonista da novela, designado por dois nomes, Olívio e Felício, nasce em Goa e, segundo António Cirurgião,

[...] acaba por estabelecer-se numa Arcádia pastoril, nas margens do Nabão, na sua confluência com o Zêzere, depois de ter deambulado pelas Ilhas Platárias ou Japão, pelo Grão Cataio ou China, pela Indochina, por Ceilão, pela Taprobana, pela ilha Formosa, pela Etiópia ou costa oriental da África, pelas ilhas de Santa Helena, por Lisboa, por Aveiro, por Coimbra. (CIRURGIÃO, 1995, p. XXXI)

É, portanto, um texto que apresenta como protagonista um goês, sendo grande parte de sua ambientação no império português na Ásia, ainda que as questões ali focalizadas se estendam para muito além desses aspectos do texto. É, evidentemente, uma obra formalmente vinculada à tradição literária portuguesa e europeia, e seu tema se liga ao contexto do império português, mas, se estudada a partir de seu possível diálogo com a realidade goesa, o que ainda está por se fazer, talvez pudesse apresentar aspectos originais e reveladores. É isso que pretende este artigo $^{2}$, mas em relação à literatura mais recente, a partir do século XIX, pois será este o momento inaugural daquela que podemos chamar, com toda propriedade, de poesia goesa de língua portuguesa.

Desde o primeiro momento do liberalismo português, em 1821, quando as publicações, em Goa, puderam sair de seu longo silêncio de cerca de um século, foi trazida de Bombaim uma imprensa para que fosse publicada a Gazeta de Goa. Na sequência, várias outras publicações de natureza menos oficial passaram a surgir estampando também matéria literária, como A Bibliotheca de Goa (Goa, jan., 1839), redigida por João Antônio de Avelar, ou O Encyclopedico - Jornal d'Instrucção e Recreio (1841-1842), dirigido por Cláudio Lagrange Monteiro Barbuda, e que foi, segundo Miranda (1863, p. 110), "o pequeno Panorama3 da litteratura indiana", ou ainda $O$ Compilador (1843-1847), semanário pitoresco, redigido pelo mesmo João Antônio de Avelar de A Biblioteca de Goa. Todas essas eram publicações que reproduziam textos oriundos da Europa, sobretudo de Portugal. Não havia qualquer matéria de autoria dos próprios goeses ${ }^{4}$. 
A produção original realizada por goeses começa a surgir ainda durante o segundo momento de publicação de O Compilador, quando apareceu o primeiro periódico cultural, como diríamos hoje, com matérias assinadas por autores goeses: O Gabinete Litterario das Fontainhas (18461848). Era voltado predominantemente para a disciplina da história e, no âmbito da literatura, ainda predominava a reprodução de textos europeus, com um ou outro texto original. Alguns outros periódicos seguiram-se a este e agregaram, ao seu redor, intelectuais goeses, introduzindo pouco a pouco a poesia, a crônica, o conto, todos de cunho local.

A paulatina criação de um meio literário goês ganhou, de fato, expressão com o surgimento da revista Ilustração Goana, periódico mensal publicado em Margão de novembro de 1864 a dezembro de 1866. Seu diretor, Júlio Gonçalves, contava com a colaboração de diversos intelectuais goeses, como Antônio Joaquim Sócrates da Costa, Antônio Ferreira Martins, Fernando da Cunha Pinto, Caetano Francisco de Miranda, Joaquim José Fernandes Arez, José Francisco de Albuquerque, José Frederico de Assa Castelo-Branco, José Gerson da Cunha, José Maria do Carmo Nazaré, Manuel Joaquim da Costa Campos, José Mariano de Abreu, Bernardo Francisco da Costa, Felipe Nery Xavier, Antônio João Frederico Gonçalves de Figueiredo, irmão do editor, entre outros; nomes que fariam a história intelectual e artística nos anos seguintes.

Segundo A literatura indo-portuguesa, de Vimala Devi e Manuel de Seabra, a Ilustração Goana foi "a revista literária que maior influência teve na vida cultural do país" (1971, v.1, p. 143). Nela, estudos originais e didáticos passaram a ser publicados, apresentando autores como Madame de Staël, Chateaubriand, Lamartine, Victor Hugo, Walter Scott, Byron, Ann Radcliffe, entre outros.

Os poetas que mais publicaram nessa revista foram Júlio Gonçalves, Manuel Joaquim da Costa Campos e José Pedro da Silva Campos Oliveira, sendo goeses os dois primeiros, e o último, moçambicano. Este, por sinal, de retorno a Moçambique, já com a experiência de ter participado do grupo da Ilustração Goana, irá inaugurar a primeira revista literária daquela colônia, a Revista Africana. Seu primeiro número, publicado na Ilha de Moçambique em 1881, revela o caráter formador que a elite letrada goesa cumpriu naquelas paragens. Nesse sentido, vale lembrar que também uma importante publicação de Macau de meados do século, Ta-ssi-yang-kuo - Semanario macaense d'interesses publicos locaes, litterario e noticioso (1863-1866), foi criada por José Gabriel Fernandes, um goês natural de Siliom, Bardez, reforçando o quanto Goa funcionou, nessa altura, como um centro de formação do meio letrado na Ásia portuguesa.

Em 1870, o poeta português Tomás Ribeiro chegou a Goa para ocupar o cargo de secretário-geral do governo e ali permaneceu por pouco mais de um ano. Nesse período, foi criado o Instituto Vasco da Gama, com a missão de promover o estudo histórico e cultural de Goa. Dentre seus diver- 
sos colaboradores goeses, apenas Manuel Joaquim da Costa Campos publicou poemas, neste e em outro periódico daqueles anos, o Album Litterario (1875-1880), que também trazia colaborações do poeta Cristóvão Pinto.

Entre os poetas que estrearam nesse momento e aqueles que já vinham publicando trabalhos desde a Ilustração Goana, vale lembrar Joaquim Mourão Garcês Palha, Tomás de Aquino Mourão Garcês Palha, Joaquim Filipe Nery Soares Rebelo, José Joaquim de Carvalho, Leandro Xavier Pereira, Guilherme Moniz Barreto e Floriano Barreto. Nessa altura, já se tem um meio literário suficientemente constituído para garantir a continuidade da produção poética goesa.

Um dos textos que mais amplamente tratou da poesia e de toda a literatura goesa de língua portuguesa é o já citado A literatura indo-portuguesa, de 1971, de Vimala Devi e Manuel de Seabra, assim como o livro de Joana Passos, Literatura goesa em português nos séculos XIX e XX: perspectivas pós-coloniais e revisão crítica (2012). Remetemos o leitor a essas obras para o conhecimento mais aprofundado desses poetas.

Interessa-nos, no presente trabalho, estabelecer algumas comparações entre a poesia goesa de língua portuguesa e outras literaturas de língua portuguesa, nomeadamente a brasileira e a moçambicana, no intuito de simplesmente assinalar o quão profícua pode ser tal comparação e, assim, reafirmar a necessidade de recuperarmos a literatura produzida naquela antiga colônia portuguesa na Índia, ainda praticamente desconhecida.

Tomemos aqui dois autores: um do século XIX e outro do XX para pensarmos essa poesia. Vejamos primeiramente um poema do já mencionado Manuel Joaquim da Costa Campos, intitulado "Á despedida da Exmª. Senhora” e publicado no Tirocinio Litterario, em abril de 1862 (p. 37):

Ai meu Deus! em fim tu partes,

Vaes deixar a terra amada,

Tão bella, tão encantada,

A terra de teu paiz!

Onde á sombra da palmeira,

Repousaste feiticeira,

E do Mandovy á beira

Folgaste outrora feliz

Porque partes, porque deixas

A terra dos teus amores,

Da infancia, da luz, das flores.

Tão formosa a rescender,

Para ires tão distante,

Pelo mar vasto, inconstante,

De perigos abundante,

Em outra terra viver?

Cruel fado é quem too obriga,

Diz-mo o pranto doloroso,

Tão amargo, e tão saudoso, 
Que te vejo deslisar!

E tu has de ainda, qu'rida,

Mar em fóra, a alma ferida,

E saudades combatida,

Mais lagrimas derramar.

Tu vaes, senhora, tu partes,

Mas tua imagem formosa,

Como d'uma irmã saudosa

Na minha alma viverá.

E do bem que aqui fizeste,

Dos martyrios que soffreste,

O perfume, anjo celeste,

Para o céu voando irá.

E confia em Deus clemente,

Não tires do pensamento,

Que has de ir em salvamento

Ás terras de Portugal;

E em paga do quanto és boa,

Lá nos jardins de Lisboa

Serás mais feliz que em Goa,

Do que na terra natal.

Mas a dita nem o tempo

Não farão em ti effeito,

E olvidar-te do teu peito

Pelo Tejo o Mandovy?

Alguma hora tu não has de

Recordar-te com saudade

Desta terra, da amisade,

E de quanto é caro a ti?

Oh que has de!.. e talvez dando

Uma lagrima sentida,

Queiras ver a patria q'rida

Do teu nobre coração!..

Mas talvez de mim coitado

Por ti seja deslembrado,

Eu que a ti hei tanto amado

Com amor puro d'irmão.

E por isso eu te offereço

Neste canto uma lembrança,

Que me dê a doce esp'rança

De saudade ao trovador.

- Eu bem sei não tem encanto,

Mas acceita que elle é santo

- Que é regada do meu pranto -

Esta humilde e pobre flor!

Nova-Goa, 25 de fevereiro de 1861 
O trânsito entre a colônia e a metrópole é recorrente na literatura goesa de língua portuguesa, aqui abordado pelo enfoque do desterro, do exílio, do abandono da terra natal. Na caracterização de Goa, aparece a sombra da palmeira, a luminosidade, as flores, o rio Mandovi, em cuja foz se encontra Panaji, a capital goesa. Todos os elementos são da natureza tropical, sem qualquer referência à cultura hindu ou a qualquer outro aspecto que particularizasse Goa em relação às outras colônias de Portugal.

Se olharmos para a forma como os poetas brasileiros fizeram sua representação nacional - nomeadamente Gonçalves Dias e sua "Canção do exílio" - ou como, por exemplo, o moçambicano Campos Oliveira, contemporâneo, como vimos, de Manuel Joaquim da Costa Campos e de Gonçalves Dias, qualificava Moçambique em seus poemas, como em "O pescador de Moçambique”, veremos que a natureza é uma constante em todos eles.

Há, no entanto, distinções. Enquanto Campos Oliveira e Costa Campos se prendem somente à natureza para qualificar seus respectivos lugares de origem, Gonçalves Dias e os brasileiros utilizaram também a figura do índio, motivados pela necessidade de marcar uma distinção de origem para o povo brasileiro em relação ao antigo colonizador português.

A poesia de Goa também acabou por assim proceder mais tarde, quando, já no início do século XX, no período da primeira república portuguesa, entre 1910 e 1926, um movimento de retorno às raízes culturais hindus apareceu de maneira bastante forte, tendo em seu horizonte o fim do colonialismo lusitano na Índia, entre outros propósitos.

O paralelo desse movimento com o indianismo brasileiro foi desenvolvido, por exemplo, por Devi \& Seabra (1971, v. 1, p. 314), e também mais recentemente por Joana Passos (2012, p. 266). Vejamos o poema intitulado "Viassa", de Paulino Dias, a maior expressão dessa vertente literária em Goa:

Eu tive um sonho. Vi o topo do Himalaia.

- Picava-o o vento largo! E era um fragor de guerra,

Choques, gritos de leões, clarins, ondas na praia...

- Em volta da Ariavarta, a milagrosa terra.

Escuro. E só o monte a erguer-se de atalaia.

Mas alguém era aí com o escopro, o malho e a serra,

Numa fúria que não abate e não desmaia,

A cortar, a ferir os pedaços da serra.

E gritei a tremer, agitado de frio:

- Quem é aí no pavor que amedronta e assombra,

A cortar e a rugir sobre um monte sombrio? - 
Era então o luar um crescente de prata.

E ouvi dizer-me alguém pelo meio da sombra:

- É Viassa a esculpir o imenso Mahâbhârata.

(apud DEVI \& SEABRA, 1971, v.2, p. 162)

O poema fala de Viassa, suposto autor do Mahabharata e muitas vezes considerado o copista dos Vedas, Puranas e Upanishadas. Portanto, sua figura está ligada aos textos mais canônicos da cultura hindu. Trata-se, assim, de um poeta clássico indiano e de sua produção poética.

Paulino Dias emprega em sua segunda estrofe a palavra Ariavarta para designar a Índia, que significa "país dos arianos", referindo-se ao fato de a história da Índia estar marcada por uma grande invasão ariana, que teria ocorrido por volta de 2000 a.C. Aos olhos dos europeus, nomeadamente dos portugueses, essa lembrança vem afirmar uma matriz comum entre indianos e europeus, que o poeta faz questão de assinalar.

Reporta-se, sobretudo, ao Himalaia, que já naquela altura fazia parte do Nepal. No entanto, a referência vem via Mahabharata, cuja ação se passa, em parte, naquela cadeia de montanhas. No poema de Paulino Dias, Viassa compõe o Marabharata como se esculpisse as montanhas do Himalaia, dando, assim, a medida de grandeza dessa composição poética.

Se compararmos tal poema com "I-Juca-Pirama", de Gonçalves Dias, por exemplo, teremos aspectos comuns. O poema do escritor brasileiro assim se inicia:

No meio das tabas de amenos verdores,

Cercadas de troncos - cobertos de flores,

Alteiam-se os tetos d'altiva nação;

São muitos seus filhos, nos ânimos fortes,

Temíveis na guerra, que em densas coortes

Assombram das matas a imensa extensão.

São rudos, severos, sedentos de glória, Já prélios incitam, já cantam vitória, Já meigos atendem à voz do cantor: São todos Timbiras, guerreiros valentes! Seu nome lá voa na boca das gentes, Condão de prodígios, de glória e terror!

As tribos vizinhas, sem forças, sem brio, As armas quebrando, lançando-as ao rio, O incenso aspiraram dos seus maracás: Medrosos das guerras que os fortes acendem, Custosos tributos ignavos lá rendem, Aos duros guerreiros sujeitos na paz.

[...]

(apud TEIXEIRA, 2008, p. 1673). 
Nesse longo poema, há uma evidente preocupação em valorizar a matriz cultural dos indígenas brasileiros, no caso, os tupis e os timbiras, por sua força e bravura, mas também por pureza e generosidade. Do mesmo modo, o hinduísmo é apresentado no poema de Paulino Dias, uma vez que, por meio dele, se reconhece a grandeza daquela cultura na metonímia do Mahabharata. Há obviamente distinções que ultrapassam as opções poéticas de cada autor e texto. Os brasileiros recriaram de uma forma bastante europeizada um universo indígena do qual tinham pouca informação e conhecimento, enquanto os poetas goeses tinham muita informação sobre a cultura hindu e a utilizavam de diversas formas.

O sentido político dessas abordagens também é diverso, já que os brasileiros pretendiam forjar um traço distintivo de seu caráter nacional, enquanto os goeses tinham vários propósitos diferentes em seu horizonte que ainda não estão devidamente estudados e, que, de poeta para poeta, poderiam ser: fazer oposição ao colonialismo português; demonstrar que são mais indianos que portugueses; demonstrar que podem viver com identidades distintas sem que isso gere conflito, entre outros.

Se compararmos com Moçambique, temos um quadro ainda mais complexo, pois será com a geração de José Craveirinha, entre as décadas de 1950 e 1970, que encontramos uma poesia com alguma similaridade programática com as de Goa e do Brasil acima mencionadas. Todavia, a peculiaridade dessa poesia moçambicana é que jamais se entendeu como poesia “indianista", isto é, como uma poesia que, de uma forma ou de outra, assumisse como elemento distintivo uma identidade que lhe é estranha, ao menos em parte: é o caso dos escritores brasileiros (majoritariamente brancos e europeizados) em relação aos índios e o dos escritores católicos goeses em relação à tradição hindu. A geração de Craveirinha foi autora de uma literatura que possuía forte vínculo com as raízes culturais daqueles escritores, além de estar ligada à internacionalização do movimento negro, tal qual revelam as quatro primeiras estrofes do poema "Hino à minha terra”, publicado em 1964, no livro Xigubo:

O sangue dos nomes

é o sangue dos homens.

Suga-o tu também se és capaz

tu que não nos amas.

Amanhece sobre as cidades do futuro.

E uma saudade cresce no nome das coisas

e digo Metengobalame e Macomia

e é Metengobalame a cálida palavra

que os negros inventaram e não outra coisa Macomia.

E grito Inhamússua, Mutamba, Massangulo!!!

E torno a gritar Inhamússua, Mutamba, Massangulo!!!

E outros nomes da minha terra

afluem doces e altivos na memória filial

e na exacta pronúncia desnudo-lhes a beleza. 


\section{Chulamáti! Manhoca! Chinhambanine!}

Morrumbala, Namaponda e Namarroi

e o vento a agitar sensualmente as folhas dos canhoeiros

eu grito Angoche, Marrupa, Michafutene e Zóbuè

e apanho as sementes do cutlho e a raiz da txumbula

e mergulho as mãos na terra fresca de Zitundo.

Oh, as belas terras do meu áfrico País

e os belos animais astutos

ágeis e fortes dos matos do meu País

e os belos rios e os belos lagos e os belos peixes

e as belas aves dos céus do meu país

e todos os nomes que eu amo belos na língua ronga

macua, suaíli, changana,

xitsua e bitonga

dos negros de Camunguine, Zavala, Meponda, Chissibuca

Zongoene, Ribáuè e Mossuril.

- Quissimajulo! Quissimajulo! - gritamos

nossas bocas autenticadas no hausto da terra.

- Aruángua! - Responde a voz dos ventos na cúpula das micaias.

[...] (apud KUNESOVÁ, 2004, p. 142-143)

Mariana Kunešová, que estudou o poema da perspectiva da tradutologia, assim se refere às estratégias identitárias presentes no texto:

O poema "Hino à minha terra" representa um dos textos fundadores da literatura moçambicana. Foi escrito entre 1950 e 1964, isto é, naquele momento crucial da existência das letras do país - na fase da sua própria constituição. $\mathrm{O}$ texto é excepcional por uma celebração visceral de Moçambique e da África, como um manifesto da singularidade e identidade do país e do continente. Ao mesmo tempo trata-se de um marco radical no que toca à emancipação da literatura moçambicana do ponto de vista da língua. Quer dizer, os setenta e nove versos do poema contêm perto de oitenta palavras de origem autóctone, nomeadamente na língua ronga. (KUNEŠOVÁ, 2004, p. 140)

Esse emprego denso de marcas linguísticas locais, assim como a marcação da figura do negro, que dialogava com a internacionalização do movimento da negritude ${ }^{5}$, são elementos que fazem desse poema um texto simbolicamente muito mais representativo, na contemporaneidade, da identidade moçambicana do que aqueles supracitados, concebidos por goeses e brasileiros, ainda que seja preciso ter em vista que aqueles cumpriram seu papel em seus contextos específicos.

As similaridades e distinções que se podem estabelecer entre essas várias tradições poéticas em língua portuguesa são muitas. O que foi feito aqui, de forma ainda bastante incipiente, tem o simples propósito de ilustrar o potencial que existe no diálogo da literatura goesa de língua portuguesa com as outras literaturas em português, gerando novos paralelos e 
novas cronologias literárias. Para que tais comparações sejam aprofundadas e multiplicadas, é ainda necessário muito esforço.

Esperamos que, em breve, não só a poesia, mas a toda literatura goesa de língua portuguesa não seja mais vista apenas como um produto exótico, misterioso, orientalista, desconhecido, mas sim como uma legítima e original tradição literária de língua portuguesa, digna de estar em diálogo com todas as outras. Cremos que isso nos proporcionará um maior entendimento de todo o processo cultural implicado no colonialismo português, do qual, nós, brasileiros, também fomos vítimas e sujeitos.

\section{REFERÊNCIAS BIBLIOGRÁFICAS}

CÉSAIRE, Aimé. Discurso sobre a negritude. Rio de Janeiro: Editora Nandyala, 2010.

CIRURGIÃO, António. Introdução. In: ORIENTE, Fernão Álvares do. Lusitânia transformada. Lisboa: Imprensa Nacional-Casa da Moeda, 1985, p. I-LXXXII.

DEVI, Vimala; SEABRA, Manuel de. A literatura indo-portuguesa. Lisboa: Junta de Investigações do Ultramar, 1971, 2 v.

DOMINGUES, Petrônio. Movimento da negritude: uma breve reconstrução histórica. Mediações - Revista de Ciências Sociais, v. 10, 1, p. 25-40, jan-jun., Londrina, 2005.

GARMES, Hélder (org.). Oriente, engenho e arte. São Paulo: Alameda Editorial, 2004.

KUNEŠOVÁ, Mariana. Africanidade, poesia e tradução (Caso do poema "Hino à minha terra", de José Craveirinha). Sborník Prací Filozofické Fakulty Brnenské University Studia Minora Facultatis Philosophicae Universitatis Brunensis, 25, p. 139-154, Masarykova Univerzita, 2004.

MIRANDA, Jacinto Caetano Barreto. Quadros históricos de Goa. Margão: Typographia de “O Ultramar”, 1863.

MUNANGA, Kabengele. Negritude: usos e sentidos. $2^{\text {a }}$ ed. São Paulo: Ática, 1988.

PASSOS, Joana. Literatura goesa em português nos séculos XIX e XX: perspectivas pós-coloniais e revisão crítica. Vila Nova de Famelicão: Universidade do Minho / Humus, 2012.

MATOS, Artur Teodoro da; CUNHA, João Teles e (coord.). Goa, passado e presente. Lisboa: CHAM, 2012, t. 1, p. 255-270.

SANSONE, Livio. Negritude sem etnicidade: o local e o global nas relações raciais, culturas e identidades negras do Brasil. Salvador/Rio de Janeiro: Editora da UFBA/Pallas Editora, 2004. 
SENGHOR, Sédar. Liberté 1: Négritude et humanisme. Paris: Éditions du Seuil, 1964.

TEIXEIRA, Ivan. Épicos. São Paulo: Edusp/Imprensa Oficial, 2008.

ZILA, Bernd. A questão da negritude. São Paulo: Brasiliense, 1984;

Recebido para publicação em 14/11/2016

Aprovado em 27/11/2016

\section{NOTAS}

1 Hélder Garmes é professor associado de Literatura Portuguesa na Universidade de São Paulo e coordenador do projeto "Pensado Goa: uma peculiar biblioteca de língua portuguesa”, financiado pela Fapesp, e do Grupo Eça, registrado nos grupos de pesquisa do CNPq. É autor e organizador de diversos livros, tais como Oriente engenho e arte (2004), O romantismo paulista (2006), Literatura portuguesa: história, memória e perspectivas (2007), entre outros.

2 Trabalho concebido no âmbito do projeto temático "Pensando Goa" (Fapesp - Proc. 2014/1415657-8) e do projeto "História da Poesia Goesa”, do CNPq.

3 O Panorama (1837-1868) foi um periódico português que fez história. Inicialmente dirigido por Alexandre Herculano e depois por Antônio Feliciano de Castilho, transformou-se num paradigma de publicação literária e de ilustração para todas as gerações do romantismo português.

4 Estes e os comentários subsequentes que aqui tecemos acerca da formação do meio literário goês de língua portuguesa no século XIX foram retirados de Hélder Garmes, "Origem e estabelecimento da imprensa e da literatura em Goa” (GARMES, 2004, p. 15-85).

5 “O movimento da negritude foi idealizado fora da África. Ele provavelmente surgiu nos Estados Unidos, passou pelas Antilhas; em seguida atingiu a Europa, chegando a França aonde adquiriu corpo e foi sistematizado. Depois, o movimento expandiu-se por toda a África negra e as Américas (inclusive o Brasil), tendo sua mensagem, assim, alcançado os negros da diáspora" (DOMINGUES, 2005, p. 26). Há extensa bibliografia sobre o referido movimento. Ver, por exemplo, Aimé Césaire (2010), Léopond S'dar Senghor (1964), Zilá Bernd (1984); Kabengele Munanga (1988), Livio Sansone (2004). 